\title{
EL DESARROLLO DEL GÉNERO BIOGRÁFICO ENTRE LOS JESUITAS DEL PARAGUAY ANTES DE LA EXPULSIÓN DE ESPAÑA
}

CARLOS PAGE

Centro de Investigaciones y Estudios sobre Cultura y Sociedad

(Conicet-Ciecs/Unc)

\section{RESUMEN}

Los jesuitas cultivaron el género biográfico en su afán de perpetuar en la historia a sus miembros más destacados. Así se lo hizo en la provincia del Paraguay con la pasión de crear arquetipos de imitación para los jóvenes religiosos. Cada biografía fue una elaboración colectiva que tenía su origen en la Carta de Edificación que escribía un allegado y esta era reescrita como obituario en las Cartas Anuas. Fundamentalmente estos documentos, aunque no fueron los únicos, se constituyeron en el material con que contaron los historiadores del Instituto. En este trabajo centramos la producción biográfica en obras inéditas y las publicadas en los siglos XVII y XVIII, sin incluir la monumental literatura de los jesuitas expulsos.

PALABRAS ClAVE: Provincia jesuítica del Paraguay; biografías; menologio; mártires.

\section{ABSTRACT}

The Jesuits cultivated the biographical genre in an effort to perpetuate the story to its most prominent members. So did the province of Paraguay with the passion to create archetypes imitation for young religious. Each biography was a collective elaboration which had its origin in the letter he wrote Building a close and this was rewritten as obituary in Anuas Letters. Fundamentally these documents, although they were not alone, constituted the material that historians told the Institute. In this paper we focus on the biopic unpublished works and published in the seventeenth and eighteenth centuries, not including the monumental literature of the Jesuits expelled.

KEYWORDS: Jesuit Province of Paraguay; biographies; menology; martyrs. 


\section{Breve introducción}

La metodología del encomium o elogio fúnebre de la Antigüedad como género biográfico, fue cultivado y enriquecido con el tiempo aunque diferenciado del quehacer historiográfico. En una primera parte se presentan cronológicamente los datos biográficos y en una segunda, las virtudes del personaje. Sin embargo no deja de aparecer lo ficcional como expresión de la libertad creativa del escritor. Entre los griegos y romanos se destacan Plutarco (c.50-120) con su Vidas Paralelas', redescubierto con verdadera pasión en el Renacimiento ${ }^{2}$, convirtiéndose su obra en modélica del género. Su proyecto llevaba a reflejar la vida ejemplar con propósitos morales, sin caer en el panegírico, utilizando vicios y virtudes para que precisamente esta última se destaque de la anterior.

Otro escritor fundamental creemos que fue Suetonio (70-140) cuya metodología de trabajo se tuvo especialmente en cuenta en el devenir cristiano. Sigue el trazad de los relatos de vidas de Plutarco, escribiendo las De vita Caesarum $^{3}$, construidas gracias a la relación que tuvo con el emperador Adriano que le encomendó ordenar y clasificar los archivos.

Con la conversión al cristianismo del emperador Constantino (306-337) surgió la variante más significativa que tuvo el género con los escritos de la vida de santos canonizados y beatos, también llamadas hagiografías. Tenían el claro objetivo de encarnar lo sagrado en lo humano y hacerlo virtuoso para el resto de la humanidad. Se prioriza en el relato lo ejemplar, antes de lo que ha pasado realmente en la vida del personaje. La efigie póstuma es reconocida desde su infancia donde discurre el relato que se centra finalmente en el discurso sobre la virtud milagrosa. Pero destaquemos que hay una construcción colectiva y hasta institucional del personaje a través de los testimonios compilados por quienes construyen su historia, que se proyecta al lector que encuentra en su vida un espejo para identificarse.

Inicialmente el género hagiográfico conmemora a las primeras víctimas del martirio, como entre muchos otros, el obispo y mártir San Cipriano de Cartago. Biografía escrita por el diácono San Poncio, muerto en 262,

\footnotetext{
${ }^{1}$ PLUTARCO. Vidas Paralelas. Obra completa. Madrid: Editorial Gredos, 2001.

2 La primera traducción fue la de Juan Fernández de Heredia, de la orden de San Juan de Jerusalén en 1389. Su versión parcializada fue vertida al italiano. Todas las Vidas paralelas, las publicó Ulrico Han en 1471 y luego Alfonso de Palencia en 1491, después lo hizo Francisco de Encinas en 1551, que fueron completadas por Diego Gracián Alderete. Los franceses recibieron su traducción en 1559 de la pluma de Amyot, teniendo gran influencia en Rousseau; mientras los ingleses de parte de Thomas North en 1579, con notables admiradores como Hamilton, Bacon, Jonson, entre otros.

${ }^{3}$ SUETONIO TRANQUILO, Cayo. Vida de los doce césares. Obra completa. Madrid: Editorial Gredos, 1992.
} 
considerada la primera biografía cristiana ${ }^{4}$. Le siguieron San Jerónimo, San Gregorio Magno, San Sofronio, San Atanasio, San Gregorio Nacianceno y San Bernardo quienes fueron los pioneros de un fructífero devenir.

A partir de una serie de relatos hagiográficos que se acumularon a lo largo de varios siglos aparece una variedad de obras compilatorias como el Martirologio Siriaco. Aunque la conformación de la hagiografía histórica, estructurada con el nombre del santo, lugar donde se lo honra, calendario y resumen de su historia, lo realiza el monje benedictino San Beda el Venerable (c.672-735), un personaje particular que dividió la era Cristiana en antes y después de Cristo, además de manifestar que la tierra era redonda e inventar en la historiografía la nota al pie de página.

En el siglo XIII aparece otra obra fundamental de la hagiografía, escrita por el italiano y beato dominico Jacques de Vorágine (1230-1298), con gran vocación didáctica y cuya influencia se extendió a lo largo de un milenio de cristiandad. Poco después el Papa Gregorio XIII propuso en 1583 la edición oficial del martirologio romano, redactado por una comisión especial que encabezó el cardenal César Baronio. Destaquemos que una edición de este libro, traducción en castellano del jesuita Dionisio Vázquez fue el primero que se publicó en la imprenta de la reducción guaranítica de Loreto en 1700 y que solo se conserva parte de un ejemplar ${ }^{5}$.

En todo este discurrir del tiempo, también hasta se llegó a escribir sobre santos que no existieron ${ }^{6}$. Aparece entonces la mayor transformación de la hagiografía que la dieron los jesuitas, desde Heribert Rosweyde, continuado por los también ignacianos, el belga Jean Bolland (1596-1665) y el holandés Godfried Henskens (1601-1681) que publicaron en 1643 los dos primeros volúmenes dedicados al mes de enero de los Acta Sanctorum con los documentos reunidos por Henskens ${ }^{7}$. Se conforma desde entonces la escuela

${ }^{4}$ CARTAGO, Cipriano de. Cartas. Introducción, traducción y notas de Ma. Luisa García Sanchidrián. Madrid: Editorial Gredos, 1998.

${ }^{5}$ Se sabe que la edición fue muy defectuosa y que incluso no hay precisiones sobre si se terminó de imprimir. En 1993 se hallaron 138 páginas de las 340 que se estima tenía el libro en la reducción de Concepción en Chiquitos (Bolivia). MAEDER, Ernesto J. A.. El Martirologio romano. Hallazgo del primer libro impreso en el Río de la Plata. Idea Viva, Gaceta de Cultura, Buenos Aires, n. 17-18, pp. 46-47, 2001.

${ }^{6}$ En 1966 bajo el papado de Paulo VI fueron excluidos del martirologio romano 33 santos que nunca se pudo comprobar si existieron, prácticamente todos mártires de los primeros tiempos muy conocidos, como por ejemplo San Valentín, San Cristóbal, San Jorge (patrono de Inglaterra, Alemania y Portugal), Santa Verónica, Santa Bárbara Mártir (patrona de Cuba), entre otros. Publicada su edición típica (Martyrologium Romanum: Conforme al decreto del Concilio Vaticano II y aprobación de Juan Pablo II. Roma: Tipografía Vaticana, $2^{a}$ edición revisada, 2004).

${ }^{7}$ En 1658 aparecieron tres volúmenes correspondientes al mes de febrero. Fue cuando se sumó Daniel Van Papenbroeck y en 1668 se publican los tres volúmenes de marzo y los de abril en 1675. Para el mes de mayo se editaron siete volúmenes, publicados entre 1680 y 1688 . Para los del mes de junio, los cinco primeros volúmenes se imprimieron en 1695, 1698, 1701, 1707 y 1709. Los últimos volúmenes de junio, julio y tres de octubre se editaron en 1770 . Tres años después se produce la supresión de la Compañía de Jesús y recién en 1837 se reanuda la sociedad de lo bolandistas en Bruselas y en 1845 publican el tomo séptimo de octubre, mientras que los restantes hasta el decimosegundo se publican entre 1853 y 1867 . El tomo decimotercero aparece recién en 1883. Los volúmenes de noviembre se publican entre 1887 y la totalidad de la obra impresa hasta ese momento se publica en 68 volúmenes en 1940. 
de los bolandistas que tendrán una lectura crítica y erudita sobre la hagiografía y quienes realizaron los primeros expurgos del exceso de apócrifos.

Con la hagiografía debemos diferenciar los martirologios que son más bien, breves noticias del martirio o de la vida del santo, repartidos por los días de su conmemoración litúrgica, que suele ser el mismo día de su muerte, o mejor de su "nacimiento" a la vida nueva. Pero también aparecen los menologios de vidas de religiosos que pueden o no ser mártires canonizados. Incluso estas "vidas ilustres" comenzaron a aparecer en cada orden religiosa, siendo la obra censurada o revisada por la superioridad previamente a su publicación. Constituyen un verdadero florilegio de una serie de hombres elegidos justamente por sus virtudes religiosas. De tal manera que tanto el clero secular como el regular promovieron este tipo de obras tendientes a crear arquetipos de imitación en los jóvenes religiosos, y los jesuitas no demoraron en ponerse al frente ante una labor evangelizadora digna de ser recordada en los trabajos de sus obreros.

\section{Las biografías de jesuitas}

Si bien dentro del Instituto surgieron escritores dedicados especialmente al género biográfico, la construcción del mismo, sea o no llevado al menologio, tiene un proceso de elaboración colectiva. Pues parten de una primera información de la muerte, sobre todo si es violenta, redactada por un compañero cercano, que la dirige al Provincial. Este panegírico laudatorio o Carta de Edificación a su vez puede resumirla o ampliarla y enviársela directamente al General si el personaje tiene fuerte presencia y se lleve la causa a Roma para una eventual beatificación y canonización. Pero también y en todos los casos el Provincial incluye un resumen de la biografía en una sección sobre necrológicas insertas en las Cartas Anuas, que actuarán luego como fuente principal para los historiadores.

Los estilos literarios obviamente sufrieron una transformación aunque no se cambia el objetivo que, como escribe el P. Oliva en 1598, el fin que lo mueve a escribir las Vidas de Varones Ilustres jesuitas del Perú es "para que leyéndolas nuestros hermanos les sirviesen como de imágenes y relatos vivos, despertador continuo para la imitación de sus heroicas virtudes" ${ }^{\prime \prime}$.

Aún antes de los bolandistas el jesuita español Pedro de Ribanedeira (1528-1611), publicó la vida de San Ignacio, compuesta entre 1567 y 1569, impresa por primera vez en 1572 en latín. Su producción, enmarcada dentro del Siglo de Oro español, va a girar entre la historia, la hagiografía y la ascética. Sus

\footnotetext{
${ }^{8}$ OLIVA, Anello. Libro primero del manuscrito original del R.P. Anello Oliva S.J. Historia del Reino y Provincias del Perú de sus Incas Reyes Descubrimiento y Conquista por los españoles de la Corona de Castilla con otras singularidades concernientes á la Historia. Escrito en 1598 y publicado, después de tres siglos por Juan F. Pazos Varela y Luis Varela y Orbegozo. Lima: Imprenta y Librería de S. Pedro, 1895.
} 
biografías son manejadas con respeto y certera verificación de las fuentes. Posteriormente escribió las biografías de San Francisco de Borja y Diego Laínez, pero se destacó su Flos Sanctorum o Libro de las Vidas de los Santos (Madrid, 1599), en dos volúmenes, editado varias veces y en diversos idiomas. Destaquemos que en lengua guaraní, traducido por el P. José Serrano, fue publicado en la imprenta de Loreto, libro que no se ha conservado ningún ejemplar.

Los jesuitas tomaron de la iglesia bizantina el término y práctica del menologio, para elogiar a sus ilustres difuntos, de acuerdo a los días y meses del calendario. Estos elogios no sólo eran de los mártires, sino también de otros miembros del Instituto. Su origen lo hallamos en las normas de correspondencia insertas por San Ignacio en las Constituciones, en donde recomendaba que los provinciales tuvieran que estar en permanente contacto epistolar con el General. Aparecen entonces las "cartas cuadrimestres" (Const. 675s), luego semestrales desde el generalato del P. Laínez en 1564 y finalmente desde el mandato de Francisco de Borja en 1565 se estableció que fueran anuales, conocidas como Cartas Anuas. Allí se incluían algunos bosquejos necrológicos de aquellos sujetos más eminentes, al principio o al final de la descripción de cada residencia, colegio o reducción. Luego fue variando el modo de escribir de acuerdo con las cambiantes Formulae scribendi que inicia el general Mercuriano. De tal manera que las Cartas del siglo XVII para el Paraguay contienen obituarios mucho más extensos y detallados que las del siglo siguiente. Pero mostrando heroicas virtudes exageradas con hechos milagrosos.

Con el tiempo se confeccionó el manuscrito Catalogo d'alcuni martyri ed altri uomini più illustri in santità della Compagnia di Gesù. No se sabe con certeza, pero probablemente fue escrito por el P. Francesco Sacchini (15701625), pues fue el historiador oficial que sucedió a Niccoló Orlandini al morir en 1606. Cumplió esa función hasta 1619, justamente en el año en que se comenzó a leer el menologio después del martirologio en la casa profesa de Roma, extendiéndose al resto de las residencias y colegios. Al traducirse y difundirse el Catálogo..., comenzaron a llegar solicitudes de otras provincias para leer a sus propios hombres célebres y para ello debieron construir sus propios menologios.

Por aquella época el jesuita belga Philippe Alegambe (1652-1613), publicó un trabajo ${ }^{9}$ con material que utilizó de Pedro de Ribanedeira y ayuda de su compatriota Bolland. Pero también escribió otras obras que quedaron inéditas y editó el P. Juan Nadasi.

En la XI Congregación General de 1681 se encargó al general Carlos de Noyelle (1682-1687) que realizara un nuevo menologio, nombrando algunos escritores romanos para pulir este catálogo de faltas, errores, adiciones y supresiones, para luego remitirlo a todo el mundo. La tarea inconclusa la intentaron continuar sus sucesores Tirso González en 1691 y luego Francisco Retz en 1739, que ordenó que los delegados a la Congregación de Procuradores a Roma llevasen las listas de sujetos y observaciones. Pero fue sumamente ardua la tarea, a la que se sumó la guerra en Europa que pospuso para más adelante la

${ }^{9}$ ALEGAMBE SJ, Philippo. Mortes Illustres et gesta eorum de Societate Iesu qui in odium fidei, pietatis, aut cuiuscunque virtutis, occasione Missionum, Sacramentorum administratorum fidri, aut virtutis propugnate / ab Ethnicis, Haereticis, vel alijs, veneno igne, ferro, aut morte alia necati, nerumnisue, confecti sunt. Romae: ex Typographia Varesii, 1657. 
celebración de la Congregación. Mientras tanto y con motivo del segundo centenario de la Compañía de Jesús apareció en 1741 el manuscrito Memoria del beato fine di alcuni Padri e Fratelli Della Compagnia di Giesú, ilustri per fama di santitá. La obra consta de 150 personajes, entre mártires, generales, los primeros compañeros de San Ignacio, además de los que estaban incluidos en el martirologio. Fue un tanto mejorado y publicado en Roma en 1840 con el nombre de Menologio ovvero pie memorie di alcuni religiosi Della Compagnia di Gesú. La obra fue reeditada en 1901 retirando a los jesuitas elevados a los altares y sumando nuevos nombres del Instituto Restaurado, sumando 256 entradas ${ }^{10}$.

Reforzando los menologios van a cobrar fuerza las biografías de los Varones Ilustres. Se destacan particularmente los tres autores que conformaron los nueve volúmenes publicados entre 1643 y 1736, los PP. José Eusebio Nieremberg $(1595-1658)^{11}$, Alonso de Andrade $(1590-1672)^{12}$ y José Cassani $(1673-1750)^{13}$ quienes tuvieron gran impacto en los lectores a pesar de su carácter panegirista y carencia de crítica histórica.

No obstante aparecieron otros menologios por naciones, producto de ese reclamo que decíamos más arriba. Es el caso de Perú donde el P. Anello Oliva escribió su historia del Perú, incluyendo Varones Ilustres de la Compañía de Jesús. La obra consta de cuatro capítulos que incorporan al final la biografía de religiosos que trabajaron entre 1568 y 1628. Aunque fue autorizada en 1631 por el provincial Mastrilli Durán, el Consejo de Indias y el P. Nieremberg; el general Vitelleschi no dio la licencia para su impresión. Recién se publicó la primera parte en Lima en 1895 y el resto, es decir las biografías, quedaron inéditas. También de Perú es la obra que escribe Juan María Freylin (Sevilla, 1632) resumiendo la obra del P. Anello; biografías de jesuitas de España de Bernardo Monzón en 1659, de Nueva España de Francisco de Florencia (Barcelona, 1671), aumentado por Juan Antonio de Oviedo en 1747. Incluye españoles y americanos la obra de Giuseppe Antonio Patrignani publicada en $1730^{14}$, continuada en el siglo XIX por Giuseppe Boero.

10 REY FAJARDO SI, José del. Los jesuitas en Venezuela. Fuentes. Caracas: Pontificia Universidad Javeriana - UCAB, 2006, v. 1, p. 84.

${ }^{11}$ NIEREMBERG, Juan Eusebio. Ideas de virtud en algunos claros varones de la Compañía de Jesús, para los Religiosos de Ella. Madrid: María de Quiñones, 1643. Firmamento religioso de lucidos astros en algunos claros varones de la Compañía de Jesús. Madrid: María de Quiñones, 1644. Vidas ejemplares y venerables memorias de algunos claros varones de la Compañía de Jesús, de los Cuales es este Tomo Cuarto. Madrid: Alonso de Paredes, 1647.

${ }^{12}$ ANDRADE, Alonso. Varones Ilvstres en santidad, letras y zelo de las almas. De la Compañía de Jesús... Madrid: Joseph Fernández de Buendía (II-VI), 1666-1667.

${ }^{13}$ CASSANI, Joseph. Glorias del segundo siglo de la Compañía de Jesús, dibuxadas en las vidas, $y$ elogios de algunos de sus varones ilustres en virtud, letras, y zelo de las almas, que han florecido desde el año 1640. Tomo VII, VIII y IX. Madrid, 1734 - 1736. (Existe segunda edición en nueve tomos publicados en Bilbao entre 1887 y 1892).

14 PATRIGNANI, Giuseppe Antonio. Menologio di pie memorie d'alcuni religiosi della CG... dal 1538 al 1727. 4 v. Venecia, 1730. 
También para el siglo XIX contamos con el jesuita belga Alois De Backer (1823-1883), quien fue en principio colaborador de su hermano en la compilación de la Bibliothèque des Ecrivains de la Compagnie de Jésus..., cuyos siete volúmenes aparecieron entre 1853 y 1861 . Pero las contribuciones del francés Carlos Sommervogel ${ }^{15}$ (1834-1902) fueron tan importantes que De Backer lo incluyó como coautor de la edición revisada (1869-1876). Sucedió en su labor a los hermanos de religión ya fallecidos y comenzó en Lovania una nueva edición revisada y ampliada. El primer volumen de su Bibliothèque de la Compagnie de Jésus... apareció en 1890 y acabó el noveno volumen en 1900. Los últimos tres tomos fueron obra de Pierre Bliard, Ernest M. Rivière y Ferdinand Cavallera.

En este mismo siglo se destaca finalmente la obra del P. Elesban de Guilhermy (1818-1884), que publicó un menologio en 14 tomos divididos por Asistencias, aparecidos entre 1893-1904, con otros dos volúmenes sobre coadjutores en 1911.

\section{La provincia del Paraguay y el género biográfico}

\section{a) Las obras inéditas}

La labor historiográfica jesuita es inmensa, desde memoriales, relaciones y tratados, breves noticias, cartas e informes anuales donde -como dijimos- se destacan los obituarios de las Cartas Anuas. Pero es necesario señalar el tránsito literario que hubo del Barroco a la Ilustración. Diferencias que son muy marcadas entre Francisco Jarque (1607-1691) y José Manuel Peramás (1732-1793), ubicados no sólo en ambos extremos estéticos, sino en contextos diferentes. El primero siendo testigo de los auspiciosos logros misionales y el segundo víctima directa del exilio. El Barroco como un periodo de la historia de la cultura fue considerado la decadencia del Renacimiento, siendo rehabilitado a fines del siglo XIX, ligándolo al pasado sin rupturas y con una identidad propia. Incluso luego se llegó a distinguir la primera Contrarreforma postridentina (manierismo) y el triunfalismo del Barroco, que mal se lo relacionó con el jesuitismo imbuido en la retórica y poética de origen grecolatino, con una notable diversidad en su tiempo que penetró en una población de medio y bajo nivel social. Pero en las postrimerías del Siglo de Oro Español, se produce una lenta renovación del pensamiento intelectual en concordancia con un siempre predilecto género histórico-biográfico que alcanzó una abundante producción que tuvo como corolario la gran generación humanista del destierro, inscripta dentro de la Ilustración.

Varias obras han quedado inéditas y de ellas comenzaremos mencionando la del P. Diego de Boroa que el 20 de junio de 1629 firmó una biografía del P. Alonso D'Aragona, un napolitano que llegó a Buenos Aires en 1617, falleciendo en Asunción en 1629. En el mismo legajo del Archivo Jesuítico

\footnotetext{
${ }^{15}$ SOMMERVOGEL, Carlos. Bibliothèque de la Compagnie de Jesús. Brussels: Nouvelle édition, 1890-1900.
} 
de Roma, le sigue un resumen del mencionado D'Aragona y otro del P. Marcial de Lorenzana sin fecha ni firma ${ }^{16}$. También allí encontramos la anónima relación sobre la muerte de los PP. Gaspar Osorio y Antonio Ripari ${ }^{17}$. Hay otras menciones necrológicas muy breves, pero siguen los textos de mayor importancia como la muerte del P. Diego de Alfaro, escrita como carta por el mismo P. Boroa en Córdoba, el 18 de enero de $1644^{18}$. El P. Francisco Lupercio Zurbano escribió al General una relación de ocho folios sobre la muerte del P. Pedro Romero, firmada en Córdoba el 26 de enero de $1646^{19}$. Un escrito similar de siete folios hallamos en Barcelona, en cuyo título se incluye el nombre de Mateo Fernández que murió junto con el P. Romero, pero a pesar de tener la misma fecha no está firmada ${ }^{20}$.

Un legajo especial se encuentra en Roma, que precisamente trata sobre las noticias necrológicas sucedidas entre 1598 y 1702 . En primer lugar hay un texto del P. Boroa dirigido al P. General con los elogios de varios jesuitas que podrían ser incorporados a la lista de los varones insignes de la provincia del Paraguay ${ }^{21}$. Se inicia con el recordatorio de Alonso de Barzana, sigue con Pedro de Añasco, Alonso de D'Aragona y Marcial de Lorenzana ${ }^{22}$. Las fechas que se señalan de fallecimiento no son todas correctas. Curiosamente el documento está presidido por un índice donde figuran 31 jesuitas y posiblemente esta compilación se realizó para la formación de un menologio del Paraguay. Efectivamente, luego se agregó a Ruiz de Montoya en varios folios. Pero avanzando en el legajo al fin encontramos el manuscrito titulado Elogia Patrum Sosietais Jesu Provincia Paraquaria Menologium Paraquatiae que comienza con Barzana (1530-1597), sigue con Diego de Torres (1551-1638), Diego de Boroa (1585-1657), Diego Ransonnier (1600-1636), José Cataldino (1571-1653), Simón Maceta (1577-1658), Pedro Romero (1585-1645), Gaspar Osorio (15951639), Antonio Ripari (1607-1639), Francisco Lucas Cavallero (1661-1711), Sebastián Discreti (1605-1669), Gonzalo Juste (1579-1639), Marcial de Lorenzana (1565-1632), Diego Francisco Altamirano (1626-1704), Francisco Burgés (1642-1725), Juan Antonio Solinas (1643-1683), Julián Lizardi (1696$1735)$, es decir 18 sacerdotes jesuitas, de los cuales sólo se inscribe un coadjutor el H. Gonzalo Juste $(1579-1639)^{23}$. No obstante en el legajo se

\footnotetext{
${ }^{16}$ Archivo Romano de la Compañía de Jesús (En adelante ARSI). Paraq. 11. Hist. Tomo 1 (16001695), ff. 211-216.

${ }^{17}$ Relación breve de la muerte del P. Gaspar Osorio y su compañero Ant. Ripario a la entrada de la mision del Chaco como a mediados de marzo del año 1639 (Ibid., ff. 260-261v.)

${ }^{18}$ Ibíd., ff. 263-270v.

19 Relacion de la muerte del P. P. Romero de la Compañía de Jesús a manos de los indios infieles de la Pcia. Del Itatín (Ibíd., ff. 311-314v.).

${ }^{20}$ Archivo Histórico de la Provincia Jesuítica de Cataluña (En adelante ARXIU), ACMI 02.

${ }^{21}$ El P. Furlong dejó un trabajo inédito para su colección de Escritores Coloniales Rioplatenses que se titula: "Diego de Boroa y su 'Historia de los varones Ilustres".". Pero desconocemos su paradero (GEOGHEGAN, Abel Rodolfo. Bibliografía de Guillermo Furlong SJ (1912-1974). Boletín de la Academia Nacional de la Historia, Buenos Aires, n. XLVIII, p. 493, 1975).

${ }^{22}$ ARSI. Paraq. 15. Necrolog. 1598-1702, ff. 2-3v.

${ }^{23}$ Ibíd., ff. 45-57v.
} 
insertan también una serie de extensas biografías escritas en latín dedicadas a Pedro Romero, Pedro Márquez, José Doménech, Marco Antonio D'Otaro, Juan Ignacio de Deizama (¿?), Juan Bautista Ferrufino. Con otra letra aparecen luego Francisco Ricquart, Andrés Gallego Bonillo, Nöel Berthot, Miguel Ángel Serra y Tomás Donvidas.

En este mismo legajo e inserto en el medio, se destaca la Vida del Venerable Padre Marcial de Lorenzana de la Compañía de Jesús. Apóstol del Paraná ${ }^{24}$. La obra anónima está prolijamente escrita y fechada en su portada, aunque con letra agregada, el 12 de setiembre de 1632. Está dedicada al P. Luis de la Palma, rector del Colegio de Alcalá y a los PP. y HH. de aquel establecimiento. Casi con seguridad el texto es del P. Diego de Boroa ${ }^{25}$. Luego sigue el prólogo y el texto dividido en tres libros. El primero trata sobre el nacimiento e infancia, sus estudios en el noviciado, su viaje a América y primera misa en Perú, su destino al Paraguay, sus viajes con el P. Saloni, su cargo de superior del colegio de Asunción, sus viajes a Córdoba y regreso a Asunción y persecuciones que sufre. El Libro Segundo se refiere a la llegada del P. Diego de Torres a Asunción, que le encomendó las misiones del Paraná, donde se establece y casi pierde la vida. Continúa con la visita a las misiones del obispo, luego pasa a Córdoba como rector del colegio y más tarde vuelve a Asunción. Finalmente en el Libro Tercero se refiere a las virtudes de Lorenzana, su humildad, mortificación, paciencia, fortaleza, prudencia, pobreza, caridad, obediencia y castidad.

En el archivo jesuítico de Barcelona encontramos un Catalogo de mártires de la provincia del Paraguay ${ }^{26}$, que no lleva autor ni fecha. Consta de 24 folios y los biografiados son: Roque González de Santa Cruz, Cristóbal de Mendoza, Pedro de Espinosa, Diego de Alfaro, Gaspar Osorio, Antonio Ripari, Sebastián de Alarcón, Pedro Romero, Mateo Fernández, Alonso Arias, Cristóbal Pascual, Antonio Solinas, Lucas Cavallero y Bartolomé de Blende. Este catálogo, como vemos, adolece de la mención de algunos jesuitas. Entre ellos nada menos que los primeros mártires del Paraguay, los PP. Martín Alonso Aranda y Horacio Vecchi que murieron en Chile junto al H. Diego de Montalbán en 1612, es decir, cuando Chile pertenecía a la provincia del Paraguay. Pues seguramente no se los mencionó ya que posteriormente Chile se desprendió de la misma. Hay un orden cronológico, pero un poco desprolijo ya que el P. Mendoza muere antes que el P. Espinosa. Igualmente se inserta al asunceño Sebastián de Alarcón que, si bien fue asesinado por los chiriguanos en 1639, para entonces se preparaba para ingresar al Instituto. Cuando se refiere a "Cristóbal Pascual", debe leerse Cristóbal Arenas, muerto en 1649. Luego de Arenas omite dos mártires como Lucas Pizarro (†1666) y Nicolás Mascardi (†1674), pues se lo hace porque en ese entonces los lugares donde mueren eran parte de la provincia chilena. Finalmente concluye con el P. De Blende, muerto en

\footnotetext{
${ }^{24}$ Ibíd., ff. 64-229v.

${ }^{25}$ El P. Luis de la Palma (1560-1641) fue un notable escritor ascético y místico al que debemos su Historia de la Sagrada Pasión, escrito en el Colegio Imperial de Madrid. Fue dos veces provincial de Toledo (1614-1617 y 1624-1627), pero en la época que ingresó el P. Boroa (1605) era justamente maestro de novicios, mientras que rector lo fue por primera vez entre $1607 \mathrm{y}$ 1610.
}

${ }^{26}$ ARXIU. AC MI 03 Chaco Argentino, ff. 441-464. 
setiembre de 1715, pues al no incluir al P. Francisco de Arce que murió en diciembre del mismo año, creemos que el escrito fue redactado justamente después de setiembre y antes de diciembre de ese año.

Finalmente en la Biblioteca Nacional de Brasil se encuentra la Carta de Edificación o Vida del P. Lauro Núñez ${ }^{27}$, fechada en 1719, es decir escrita en el mismo año de su fallecimiento, seguramente como primer testimonio dirigido al Provincial para volcarlo en las Cartas Anuas. Otras biografías inéditas son la de Ios PP. Francisco Lucas Cavallero y se ubica en el repositorio romano, escrita el 28 de setiembre de 1711, diez días después de su martirio en Chiquitos, aunque desconocemos su autor ${ }^{28}$. También se encuentra inédita la biografía del P. Francisco Burgés, redactada en 1726 por el P. Luis de la Roca, rector por entonces del Colegio Máximo de Córdoba, cuyo original se halla en la Biblioteca Nacional de España ${ }^{29}$. Hay una copia en el Archivo de los jesuitas de Alcalá de Henares y el P. Pastells publicó un resumen en su conocida obra ${ }^{30}$.

\section{b) Las obras editas y los primeros trabajos del siglo XVIII}

El P. General Claudio Aquaviva (1581-1615) en sus últimos años de gobierno había encomendado a las provincias jesuíticas que redactaran sus historias. La tarea comenzó a tener eco lentamente. De ahí sabemos que el primer historiador del Paraguay fue el P. Juan Pastor (1582-1658) cuya obra fue terminada en 1649 , y que posiblemente haya incluido biografías. Lo cierto es que el P. procurador Ferrufino llevó los dos tomos a Roma para que sean debidamente censurados. Pero el jesuita general alemán Goswin Nickel (16521664), si bien en principio le concedió la ayuda del H. Diego Chaves como amanuense y recibió positivas críticas, luego no creyó conveniente publicar la obra porque mencionaba a personas aún en vida, como el polémico obispo Cárdenas y sus partidarios. Por tanto el manuscrito no se imprimió y se perdió $^{31}$. No sabemos si el P. Pastor escribió biografías, pero el género no dejó de estar presente en diversos relatos como en la obra de Antonio Ruiz de Montoya (1639), que no es estrictamente histórica, más bien una autobiografía que debió escribir apresurado y como informe por pedido de la Corona, que incluye la vida de los martirios del P. Espinosa y de los santos del Caaró.

\footnotetext{
${ }^{27}$ Biblioteca Nacional de Brasil, Río de Janeiro (En adelante BNB), Ms. 508 (23) doc. 580, I-29, $9,1$.

${ }^{28}$ Breve noticia de la muerte del Venerable P. Lucas Caballero q. murió a manos de los Barbaros en las Missiones de Chiquitos (ARSI. Paraq. 12. Hist. (1667-1785), ff. 56-57).

${ }^{29}$ Biblioteca Nacional de España (En adelante BNE), Ms. 19582.

30 PASTELLS SJ, Pablo. Historia de la Compañía de Jesús en la Provincia del Paraguay (Argentina, Paraguay, Uruguay, Perú, Bolivia y Brasil) según los documentos originales del Archivo General de Indias. Madrid: Librería General de Victorino Suárez, 1933, t. V, pp. 43-52.

${ }^{31}$ BEGUIRIZTÁIN, Justo. El P. Juan Pastor y su inédita historia de la provincia del Paraguay. Estudios, Buenos Aires, n. 75, pp. 147-155, 1946.
} 
Pero más específico en incluir historias de vidas dentro de una historia general del Paraguay va a ser el francés, P. Nicolás Del Techo (1611-1685). Fue misionero y superior entre los guaraníes (1672-1676), maestro de novicios (1671) y rector del colegio de Asunción (1678-1679). En 1648 el general Vicente Caraffa le concedió la licencia para escribir la historia de su provincia, que recién terminó en 1657 y se publicó por primera vez en latín en el principado de Lieja en $1674^{32}$. Su pionera obra fue muy criticada por su estilo artificial y el abuso en la aceptación de milagros, pero no debemos olvidar en el contexto en que escribe, el reconocimiento a sus méritos y de haber sido testigo directo de varios de los acontecimientos que relata. Posiblemente como escribe Lozano haya leído los manuscritos de Pastor, pero Del Techo reconoce como sus inspiradores a los PP. Diego de Boroa y Francisco Díaz Taño. En su texto se incluyen varias biografías, pues le interesan más los hombres que los hechos y la materia biográfica fue luego fundamental en su labor historiográfica. Pues posteriormente fueron compiladas en 1759, en la obra titulada Decades virorum... ${ }^{33}$. Este libro en realidad y como lo señaló el P. Furlong ${ }^{34}$ en su momento, consta de una primea parte de 375 páginas compuesta por Del Techo y una segunda de 173 páginas, por Ladislao Orosz. Antes de los textos de Del Techo se encuentra la autorización de edición, un prólogo de sólo dos páginas (Premonitio. Ad benevolum Lectores) y luego una cronología histórica de la provincia del Paraguay de 38 páginas que se inicia con el descubrimiento de América y termina en 1645, por lo que seguro la escribió el P. Del Techo. Ordenadas cronológicamente en latín, Del Techo escribe cinco "décadas" o capítulos compuestas por diez biografías cada una. Mientras el P. Orosz le incorpora otras cuatro "décadas" con otras diez biografías cada una, excepto una con nueve. Es decir que en total suman 89 biografías. En el mismo libro se aclara al principio que un profesor de Tyrnavia ${ }^{35}$ enmendó algunos puntos del texto de Del Techo y ordenó los papeles de Orosz para que fueran impresos. Según Furlong ese profesor fue un amigo de Orosz, llamado Nicolás Schmith que era por entonces rector de la universidad de Tyrnavia, que se encargó de la edición llevada especialmente por Orosz a Europa cuando fue procurador de la provincia del Paraguay (1746-1749). El P. Orosz quedó que próximamente completaría la obra con más envíos para que fueran impresos en la universidad, pero no lo hizo ${ }^{36}$. Una acotación final, más que interesante, pues el ejemplar que consultamos en la biblioteca de los bolandistas en Bruselas es uno de los dos únicos que existe en el mundo ${ }^{37}$. Lo explica el bibliógrafo jesuita Stoeger

32 FURLONG SI, Guillermo. Nicolás del Techo, autor de la primera 'Historia jesuítica del Paraguay', 1611-1685. Estudios. Buenos Aires, n 83, pp. 17-30 y 163-188, 1950. STORNI SI, Hugo. Jesuitas valones, flamencos y franceses, misioneros en Paraguay, 1608-1767. Archivum Historicum Societatis Iesu, 49, Roma, 1980, n. 48, pp. 417-431.

${ }^{33}$ DEL TECHO SI, Nicolás y OROSZ, Ladislao. Decades virorum illustrium Paraquariae Societatis Jesu. Ex Historia ejusdem Provinciae, et aliunde depromtae... Tyrnavia: Typis Academicis Societatis Jesu, 1759.

${ }^{34}$ FURLONG SI, Guillermo. Ladislao Orosz y su "Nicolás del Techo" (1759). Buenos Aires: Ediciones Theoría, 1966, pp. 85-86.

${ }^{35}$ Tyrnavia = latín por Tyrnava, alemán Tirnau, hoy "Trnava" (Eslovaquia).

${ }^{36}$ SZABÓ, Ladislao. El húngaro Ladislao Orosz en tierras argentinas 1729-1767. Buenos Aires: FECIC, 1984, p. 103.

${ }^{37}$ Ibíd, p. 146. 
expresando que los superiores de Roma decidieron una vez impreso el libro y viendo que las circunstancias no eran favorables a los jesuitas, suponemos ante tanta extravagancia en número de biografiados, ordenaron que se destruya la obra. Lo cierto es que no se trataba específicamente del contenido, sino de la significativa fecha de publicación (1759). Coincidía con la recrudecida propaganda anti-jesuítica en Europa, especialmente contra las reducciones del Paraguay, las secuelas de la guerra guaranítica y la expulsión de Instituto de Portugal (1759). Lamentablemente este singular y valioso libro nunca se volvió a editar.

Además de ello en la Biblioteca Nacional de Madrid se encuentra un manuscrito de las biografías de Del Techo. Es un curioso "libro" titulado Virirum Ilustrium... que imita la letra de imprenta, siendo profusamente decorada con viñetas. Fue confeccionado en las misiones guaraníticas, del que quizás se hayan copiado varios ejemplares. Tiene un ex-libris De la librería del Colegio de la Compañía de Jesús de Córdoba. La obra está dedicada al general Noyelle, lo que nos indica la fecha aproximada de composición (1682-1686).

Como dijimos Del Techo dedicó en su Historia de la Compañía del Paraguay varias biografías, pero en una publicación de Juan Bautista Lanciego (1716) ${ }^{38}$ se extracta la vida de Juan de Viana y la adjunta con la de otros cinco compatriotas de Viana. También coincide con el texto de Del Techo un folleto flamenco que da cuenta de la vida del P. Bartolomé de Blende, publicado en 1718.

Cabe detenerse en las vidas de los mártires del Caaró, de quienes escribieron los PP. Ruiz de Montoya, Del Techo, Lozano y Charlevoix. Pero la primera noticia del martirio la brinda el P. Tomás de Ureña en carta que escribe al rector de Santa Fe, P. Juan de Cereceda cinco días después de la muerte. Al mes siguiente el P. Pedro Romero escribió una relación del martirio para el Provincial, a los efectos de fuera comunicada al gobernador Hernandarias. Transcripta la relación se la envió al mandatario y al general Muzio Vitteleschi. Ambos manuscritos, más otras dos copias en italiano se encuentran en el ARSI ${ }^{39}$ y el P. José Oreggi la incluye en su Relatione di alcune cose notabili... También dio noticia el P. Diego de Boroa e inmediatamente se inició el proceso de beatificación con una serie de testimonios. Pero la primera biografía impresa es del P. Francisco Crespo de $1630^{40}$. La misma fue traducida e impresa en Lille en ese año, en Viena al año siguiente y en Nápoles en 1632. El original se

\footnotetext{
38 LANCIEGO, Juan Bautista. Epitome de la vida del V.P. Juan de Viana de la Compañía de Jesús... con una addicion de otros cinco paisanos del P. Viana..., Viana: por Joseph Joachin Martinez, 1716.

39 Relación del Glorioso Martyrio de Los Santos Padres Roque González, Alonso Rodríguez y Juan del Castillo. Para el Señor Gobernador Hernandarias de Saavedra y remitida al Padre francisco Vazquez Trujillo Provincial de la Compañía de Jesús de la Provincia del Paraguay (ARSI, Paraq. 11, Hist. T.1 (1600-1695), ff. 172-178v) y Relación de la gloriosa Muerte de Los santos Padres Roque Gonzalez, Alonso Rodríguez y Juan del Castillo y lo sucedido en ella. Por el P. Franc. Vazquez Trujillo Prov. De la Compañía de Jesús en la Provincia del Paraguay. A nuestro muy R. Padre Mucio Vitelleschi Preposito General de la Compañía de Jesús (Ibíd., ff. 180-189).

${ }^{40}$ CRESPO, Francisco. Relación del glorioso martirio de los PP. Roque González, Alonso Rodríguez y Juan del Castillo. Madrid: Por Andrés Parra, 1630.
} 
encuentra en el ARSI, donde además hay un inédito Elogio del P. Alonso Rodríguez. Después ya fue incluida en la obra de Andrade, Alegambe y antes en la de Nieremberg. Mientras tanto en el Paraguay el milanés P. Juan Bautista Ferrufino, que llevó a Roma el corazón de Roque González, escribió sobre el martirio en $1633^{41}$, reeditada varias veces, e incluida en la obra de Jarque sobre Montoya. Pero también cartas, memoriales e informes como las Anuas multiplicaron las obras dedicadas a los santos, que encontraron mayor profundidad de estudios desarrollados luego de la expulsión.

Contemporáneo a Del Techo vivió el mencionado misionero jesuita Francisco Jarque (1607-1691). Llegó al Paraguay con el noviciado cumplido, en la expedición del P. Gaspar Sobrino (1628), terminando sus estudios en Córdoba, aunque abandonó la Compañía de Jesús en 1637. Al poco tiempo regresó a España y con el oficio de deán de la catedral de Albarracín en Teruel, dedicó sus años a escribir sobre algunos jesuitas del Paraguay, ejemplos de hombres que seguramente al recordarlos le motivaron a reincorporarse al Instituto antes de su muerte. Las obras de Jarque son eminentemente laudatorias y entre estas cabe mencionar la vida de los PP. Montoya (1662) y Cataldino $(1664)^{42}$. Aunque sobresale Insignes misioneros... (1687), dividido en tres partes. La tercera fue reeditada recientemente ${ }^{43}$, mientras que las dos primeras hacen alusión a las biografías del P. Simón Mascetta (p. 1-92), que escribió en base a una perdida relación de Justo Van Suerck ${ }^{44}$ y luego una más extensa vida de Francisco Díaz Taño (pp. 93-283).

De este último jesuita, aunque volvamos a tocar las obras inéditas, es probable que sea un manuscrito, titulado Varones ilustres de la provincia del Paraguay, que se encuentra en la sección manuscritos de la Biblioteca Nacional de Madrid $^{45}$, que si bien no se consigna el autor, Furlong no descarta tal posibilidad, contrariando a Uriarte que afirma ser de Lozano. Las biografías corresponden a los PP. Diego de Boroa (1585-1657), Justo Mansilla (Josse Van Suerck) (1600-1666), Juan Pastor (1580-1658), Cristóbal Altamirano (16021698), Pedro Álvarez (1596-1653), Diego de Salazar (1592-1659), Antonio Masero (1580-1653), Juan Suárez de Toledo (1594-1675), José Oreggi (15881664) y Antonio Ordóñez (1605-1654) $)^{46}$. Lo cierto es que Furlong se funda en que son biografiados de los primeros tiempos del Instituto en el Paraguay,

${ }^{41}$ FERRUFINO, Juan Bautista. Relación del martirio de los PP. Roque González de Santacruz, Alonso Rodríguez, Juan del Castillo, de la Compañía de Jesús, padecido en el Paraguay a 16 de Noviembre de 1628. Sevilla, 1633.

42 JARQUE, Francisco. Ruiz de Montoya en Indias (1608-1652). Madrid: Victoriano Suárez editor, 1900. [Vida prodigiosa, en lo vario de los sucesos, exemplar en lo heroíco de religiosas virtudes ... Del venerable padre Antonio Rviz de Montoya, religioso profeso, Zaragoza, Juan de Ibár. 1662]. Vida apostólica del Venerable Padre José Cataldino, uno de los primeros, y mas insignes conquistadores de las dilatadas Provincias, y barbaras Naciones del Guayrá... Zaragoza: Por Ivan de Ibar, 1664.

43 JARQUE Francisco y ALTAMIRANO, Diego Francisco. Las misiones jesuíticas en 1687. El estado que al presente gozan las Misiones de la Compañía de Jesús en la Provincia del Paraguay, Tucumán y Río de la Plata. Estudio preliminar de Ernesto Maeder. Buenos Aires: Academia Nacional de la Historia - Union Académique Internationale, 2008.

${ }^{44}$ FURLONG SI, Guillermo. Justo Van Suerck y su carta sobre Buenos Aires (1629). Buenos Aires: Ediciones Theoría, 1963a, p. 64.

${ }^{45}$ BNE, Ms. 18571.

${ }^{46}$ FURLONG, 1959, p. 137. 
además de "sus buenas razones para creer que el autor" es Díaz Taño (15931677), quien fue procurador a Europa en dos oportunidades (1637-1640 y 1658-1663) y profundamente compenetrado con las misiones guaraníticas donde fue superior, también por dos mandatos (1646-1649 y 1657-1658). Pero es del caso que si bien son contemporáneos al supuesto autor, nos desconcierta la biografía de Altamirano, pues murió dos décadas después que Díaz Taño. Tampoco Jarque en la biografía que hace de él, menciona que haya escrito tal obra, aunque en la introducción se lamenta "de que se ayan dexado en el Nuevo Mundo varios tratados, que escrivio el Venerable Padre Francisco Diaz Taño ${ }^{\prime \prime 4}$. Las obras de Jarque se encontraban en la biblioteca del Colegio Máximo del Paraguay según el inventario de 1757, al igual que la de otras varias decenas de vidas ilustres, menologios, etc. Pero entre ellas cabe mencionar la obra de Juan Muñoz de Gálvez ${ }^{48}$ sobre la muerte y virtudes de Ruiz de Montoya que escribe en 28 páginas y se publica en Sevilla en 1632. El autor había sido rector del colegio de Marchena y llegó a ser provincial de Andalucía.

Volviendo a esta compilación de biografías que acabamos de señalar, hemos encontrado otra en el archivo de los jesuitas de Alcalá de Henares que, unas en latín y otras en castellano, contiene los mismos personajes aunque en diferente orden y agregando al misionero de Chiquitos P. Felipe Suárez (1663$1727)^{49}$. Acá las dudas se disipan pues el manuscrito tiene una nota que expresa que lo latino está copiado del P. Del Techo y que lo demás original está en la sección Manuscritos de la Biblioteca Nacional de Madrid, como efectivamente así lo señalamos antes.

El P. Furlong publicó en nuestro medio un documento inédito sobre la vida del P. Nicolás Mascardi. Expresa el historiador que el documento lo dio a conocer Paolo Rovelli en Italia en 1926, y Furlong lo fotografió en 1938. Lo encontró en la Iglesia del Gesú en Roma, siendo un manuscrito de 18 folios escrito a dos columnas. Es anónimo pero sabemos que tanto sus contemporáneos Diego Rosales como Antonio Alemán y Miguel de Olivares se ocuparon de reunir noticias de Mascardi. Furlong la atribuye en principio a este último, que alcanzó a ser provincial de Chile (1684-1689) y fue misionero junto con Mascardi. Mientras el mártir fundaba la reducción de los Poyas, Olivares hacía lo propio con San José de la Mocha. Una profunda amistad los unía y fue precisamente el P. Alemán el que inició la causa de beatificación de su

\footnotetext{
47 JARQUE, Francisco. Insignes misioneros de la Compañía de Jesús en la provincia del Paraguay. Estado presente de sus missiones de Tucuman, Paraguay y Río de la Plata, que comprende su distrito. Pamplona: Por Juan Micón, 1687, p. 95.

${ }^{48}$ MUÑOZ DE GÁLVEZ, Juan. Carta del padre Iuan Muñoz de Galvez, rector del Colegio de San Hermenegildo, de la Compañia de Iesus de Seuilla: para los superiores, y religiosos desta prouincia de la Andalucia, sobre la muerte, y virtudes del padre Diego Ruiz de Montoya. Sevilla, 1632.

${ }^{49}$ Archivo Histórico de la Provincia de Toledo (En adelante AHPTSJ), Ms. M-55.
} 
compañero ${ }^{50}$. Pero tiempo después el P. Furlong aclaró que se equivocó y que el autor fue Rosales (1601-1677) siguiendo lo consignado por el historiador Rosso ${ }^{51}$.

El siglo XVIII fue de una producción no menos encomiable. Ya hablamos de la importancia del libro de Del Techo y Orosz, del que sólo podrá acercarse el P. José Manuel Peramás con sus dos libros publicados en el exilio. Pero veamos algunas obras de distinta valía, principalmente por las extensiones de sus contenidos.

Así tenemos al P. Antonio Sepp, escribiendo una carta al superior de la provincia de Germania Superior con motivo de la muerte del H. Juan Krauss, constructor del templo de San Ignacio en Buenos Aires, el Noviciado y el Convictorio en Córdoba, entre varias iglesias en las reducciones. La carta la encontró Furlong en la Biblioteca de la Universidad de Munich, siendo traducida y publicada por Edmundo Wernicke ${ }^{52}$. También el mismo Sepp escribió la vida del P. Antonio Böhn, enviada al provincial Lauro Núñez y luego sabemos que se puso a traducirla al alemán. Pero no nos han llegado estos textos ${ }^{53}$. Recordemos que su compatriota nació en Baviera en 1659 y murió en la reducción de San Carlos en 1695, permaneciendo sólo cuatro años en las misiones.

El sardo Antonio Machoni dedicó un libro dando cuenta de la vida de algunos de sus compatriotas con un título muy sugestivo ${ }^{54}$. Este libro fue un verdadero obsequio para Cerdeña, pues significaba devolver la memoria de aquellos misioneros que se creían muertos y contarles que habían sido voluntariamente cautivos del amor, entregando sus vidas a grandes trabajos apostólicos $^{55}$.

${ }^{50}$ FURLONG SI, Guillermo. Vida apostólica y glorioso martirio del venerable Padre Nicolás Mascardi. Anales del Museo de la Patagonia "Francisco P. Moreno", Buenos Aires, n. 1, pp. 193235, 1945.

${ }^{51}$ Ibídem. Nicolás Mascardi S. I. y su carta-relación (1670). Buenos Aires: Editorial Theoría, 1963b, p. 101. ROSSO, Giuseppe. Nicolò Mascardi, missionario gesuita, esploratore del Cile e della Patagonia (1624-1674). Archivum Historicum Societatis Iesu, n. 19, p. 3-74, 1950.

${ }^{52}$ WERNICKE, Edmundo. Una carta del P. Antonio Sepp SJ con motivo de la muerte del hermano Juan Krauss, constructor del templo de San Ignacio. Anuario de la Sociedad de Historia, Buenos Aires, pp. 360-363, 1941.

53 FURLONG SI, Guillermo. Antonio Sepp SJ y su "Gobierno temporal" (1732). Buenos Aires: Ediciones Theoría, 1962, p. 95.

${ }^{54}$ MACHONI SJ, Antonio. Las siete estrellas de la mano de Jesus, Por el Padre Antonio Machoni de la Compañía de Jesús, natural de Cerdeña, Rector del Colegio Máximo de Córdoba del Tucumàn y Procurador General à Roma por su Provincia del Paraguay... Córdoba (España) Colegio de la Assumpcion: por Joseph Santos Balbàs, 1732.

${ }^{55}$ El P. Furlong en su colección de Escritores Coloniales Rioplatenses dejó entre otras obras inéditas: Antonio Machoni y sus "Siete estrellas de la mano de Jesús". Contaba con un total de de 850 páginas con su tradicional biobibliografia y el texto completo de la obra de Machoni en 696 páginas. También se desconoce su paradero. (GEOGHEGAN, 1975, p. 493). 
No sabemos fehacientemente si Machoni viajó a Cerdeña estando en Europa como procurador (1739-1743). No era fácil por entonces acceder a la isla, pero probablemente lo hiciera, incluso para entregar personalmente este libro publicado en España ${ }^{56}$.

El título de la obra alude a las siete estrellas que vio San Juan en la mano derecha de Jesús en el Apocalipsis, que no son otras que los astros hasta entonces conocidos. Cada uno de ellos fue identificado con los Siete Arcángeles. Así el sol con Bernardo Tolo por su ardiente fervor; la Luna por Lucas Quesa por su apacible semblante y atractivo con los infieles; Marte en Juan Antonio Manquiano por su invicta constancia y extremo valor en los trabajos y perfecciones; Venus en Juan Antonio Solinas por su amante caridad; Júpiter al P. Miguel Ángel Serra por el rayo ardiente de su apostólico celo; Saturno a Juan José Gugliermo por su admirable paciencia y Mercurio a José Tolo por su prudencia celestial en convertir y guiar las almas al cielo.

En la introducción Machoni cita a Heródoto, Séneca, Claudio, Ovidio y personajes bíblicos como Ezequiel, e incluso pasajes desde el Génesis al Apocalipsis. Sus fuentes -como él mismo lo expresa- son las Cartas Anuas y cartas particulares recibidas de allegados de los biografiados, tanto de Europa y de América. Contemporáneos y censores del libro como el P. Cristóbal de Palma, el mismo que leyó la obra de Lozano, afirmaba que el texto sigue la prolífera línea de Casiodoro y que se descubre en el autor su apostólico celo y espíritu en la imitación de estos claros varones. Se reeditó la biografía del P. Guglielmo en $1963^{57}$.

Como no podíamos menos de esperar, el P. Pedro Lozano, quien publicó obras históricas excepcionales, cultivó el género biográfico. Así aparece su trabajo sobre el $\mathrm{P}$. Julián Lizardi $^{58}$, aunque aparentemente no existe ningún ejemplar y la versión que conocemos son reediciones de 1857, 1862 y 1901. La primera fue reimpresa por un descendiente del mártir, don José Javier de Lizardi en San Sebastián $(210 \mathrm{pp})$. La tercera edición madrileña estuvo a cargo de Uriarte y Lavajos (186 pp.) y consigna que siguieron la primera edición, reafirmando que fue costeada por su familia y que se encontraba en el archivo del Cabildo Eclesiástico de Asteazu. Una cuarta edición se incluyó en el libro de Vaughan $^{59}$, quien siguiendo la edición anterior hizo en 1901 algunas modificaciones, dividiendo los textos en más títulos. Se publicó en Buenos Aires y

\footnotetext{
${ }^{56}$ El ejemplar que se encuentra en la biblioteca universitaria fue donado en 1843 por Faustino Baille y en su ex libris se lee "est domus probationis calarit Soc. Iesu", es de la Casa de Probación de Cagliari. Otro ejemplar se encuentra en la Biblioteca Nacional de Buenos Aires.

${ }^{57}$ MEDINA, José Toribio. Biblioteca Hispano Chilena (1523-1817). Tomo II 1700-1768. Santiago de Chile: Fondo Histórico y Bibliográfico José Toribio Medina, 1963, pp. 387-426

${ }^{58}$ LOZANO SI, Pedro. Relación de la Vida, y Virtudes del Venerable Martyr P. Julián de Lizardi, de la Compañía de Jesús, de la Provincia del Paraguay. Salamanca: Por Antonio Villagordo, 1741.

59 VAUGHAN, Kenelm. Descubrimiento de los restos del Venerable P. Julián Lizardi (De la Compañía de Jesís) y su traslación de Tarija á Buenos Aires... Con la Vida del Mártir por P. Pedro Lozano SJ. Barcelona: Librería de Subirana, 1901.
} 
la primera parte relata las vicisitudes del autor en hallar los restos del P. Lizardi y llevarlos al País Vasco.

El impresor Joachim Ibarra dedica una obra, aunque de menor envergadura, a la vida del P. Juan Saloni ${ }^{60}$ y aclara que siguió el texto de Lozano de la Historia de la Compañía de Jesús de 1754. Varios investigadores le adjudicaron la autoría a un tal P. Jaime Torres, pero Furlong ${ }^{61}$ es categórico en afirmar que el autor es Lozano y que su texto fue extraído de la obra mencionada.

Otro autor para destacar es el santafecino Juan de Montenegro (16961761), quien escribe la vida de su compatriota salteño Agustín Castañares ${ }^{62}$ (1687-1744) muerto mártir en el Chaco cuando se internó en busca de los mataguayos. Lo hizo junto con un poblador de Tarija llamado Francisco Azoca y un grupo de soldados e indios. Llegaron a la primera aldea y fueron bien recibidos por el cacique Gallinazo, autor de la muerte del sacerdote y de Azoca. La obra se publicó en Madrid en 1746 con 88 páginas en forma de carta que dirige al P. Ladislao Orosz el 15 de agosto de 1745 . Fue reeditada íntegra en la biografía que escribe Furlong del autor ${ }^{63}$.

\section{Algunas conclusiones}

Por una cuestión de espacio hemos prescindido de la nutrida producción de los jesuitas en el exilio que sin dudas completaría el panorama sobre los escritos biográficos de los antiguos jesuitas del Paraguay. Pero igualmente dejamos en evidencia que aquellos prestigiosos historiadores europeos, desde el baluarte jesuita del Siglo de Oro Español Pedro de Ribanedeira hasta el decimonónico y enciclopédico francés Carlos Sommervogel, se inspiraron en la copiosa producción de jesuitas Hispanoamericanos. Tanto cronistas como historiadores, compañeros de las misiones y hasta testigos de martirios, conocidos o desconocidos, no dejaron de volcar sus recuerdos en textos que tuvieron los mismos objetivos que se persiguieron desde el encomium y las hagiografías, martirologios y menologios. Es decir, dejar marcada para la posteridad la vida de quienes estuvieron junto a ellos, que dejaron sus cómodos hogares europeos a cambio de habitaciones precarias, mala alimentación y peligros diversos en sus vidas. Pues se destacaron en el afán de entregarse al otro, que no era ni más ni menos que el hombre americano.

\footnotetext{
${ }^{60}$ LOZANO SI, Pedro. Breve relación de la Vida, y Virtudes del Venerable, y Apostólico P. Juan Saloni, de la Compañía de Jesús, Celosísimo Misionero de diferentes Provincias de la América...., Madrid: Por Joachim Ibarra, 1763.

${ }^{61}$ FURLONG SI, Guillermo. Pedro Lozano, SJ y sus "Observaciones a Vargas" (1750). Buenos Aires: Librería del Plata, 1959, p. 93.

62 MONTENEGRO SI, Juan de. Breve noticia de las Misiones, peregrinaciones apostolicas, trabajos, sudor, y sangre vertida, en obsequio de la fé, de el Venerable Padre Agustin Castañares, de la Compañía de Jesús, Insigne missionero de la provincia del Paraguay, en las Missiones de Chiquitos, Zamucos, y últimamente a la mission de los infieles Mataguayos.... Madrid: Por Miguel Fernández, 1746.

63 FURLONG SI, Guillermo. Juan de Montenegro y su "Breve Noticia" (1746). Buenos Aires: Ediciones Theoría, 1964, pp. 51-101.
} 


\section{Sobre o autor}

Carlo Page é doutor em História pela Universidad del Salvador e arquiteto pela Universidad Católica de Córdoba. Investigador Independente do CONICET com sede no Centro de Investigaciones y Estudios sobre Cultura y Sociedad e diretor da Revista IHS. Antiguos jesuítas en Iberoamérica, Conicet-Ciecs.

Artigo recebido em 30 de agosto de 2014. Aprovado em 11 de novembro de 2014. 